\title{
Impacts of right ventricular trabeculae and papillary muscles on volumes and function assessed by cardiovascular magnetic resonance using a novel software: semi-automatic threshold- based segmentation algorithm
}

Akio Inage ${ }^{*}$, Naokazu Mizuno

From 18th Annual SCMR Scientific Sessions

Nice, France. 4-7 February 2015

\section{Background}

The objective of this study was to assess the impact of right ventricular (RV) trabeculae and papillary muscles on measured volumes and function assessed by cardiovascular magnetic resonance (CMR) using a novel semiautomatic segmentation algorithm in patients with right heart lesion of the congenital heart diseases. The new algorithm was based on the signal intensity distribution of MR images, and excludes trabeculae and papillary muscles from the blood pool, while the manual approach includes these objects in the blood pool.

\section{Methods}

We measured RV end-diastolic volume (RVEDV), end-systolic volume (RVESV), stroke volume (RVSV) and ejection fraction (RVEF) by CMR using standard methods of manual contour tracing and semi-automatic methods. We measured net pulmonary artery forward flow volume (PAFV) as RVSV using phase contrast (PC) MR. Also, we measured RVEDV, RVESV, RVSV and RVEF using ventriculographies including trabeculae and papillary muscles. The new algorithm was performed using the Medis novel software.

\section{Results}

There was a total of 50 cases and the mean age was $22+/-$ 18 years. By excluding the trabeculae and papillary muscle in the RV blood volume, the measured RVEDV decreased by $31 \%$ (from $175+/-64$ to $120+/-66 \mathrm{ml} / \mathrm{m}^{2}$, p $<0.005$ ),

Department of Radiology, Sakakibara Heart Institute, Fuchu, Japan

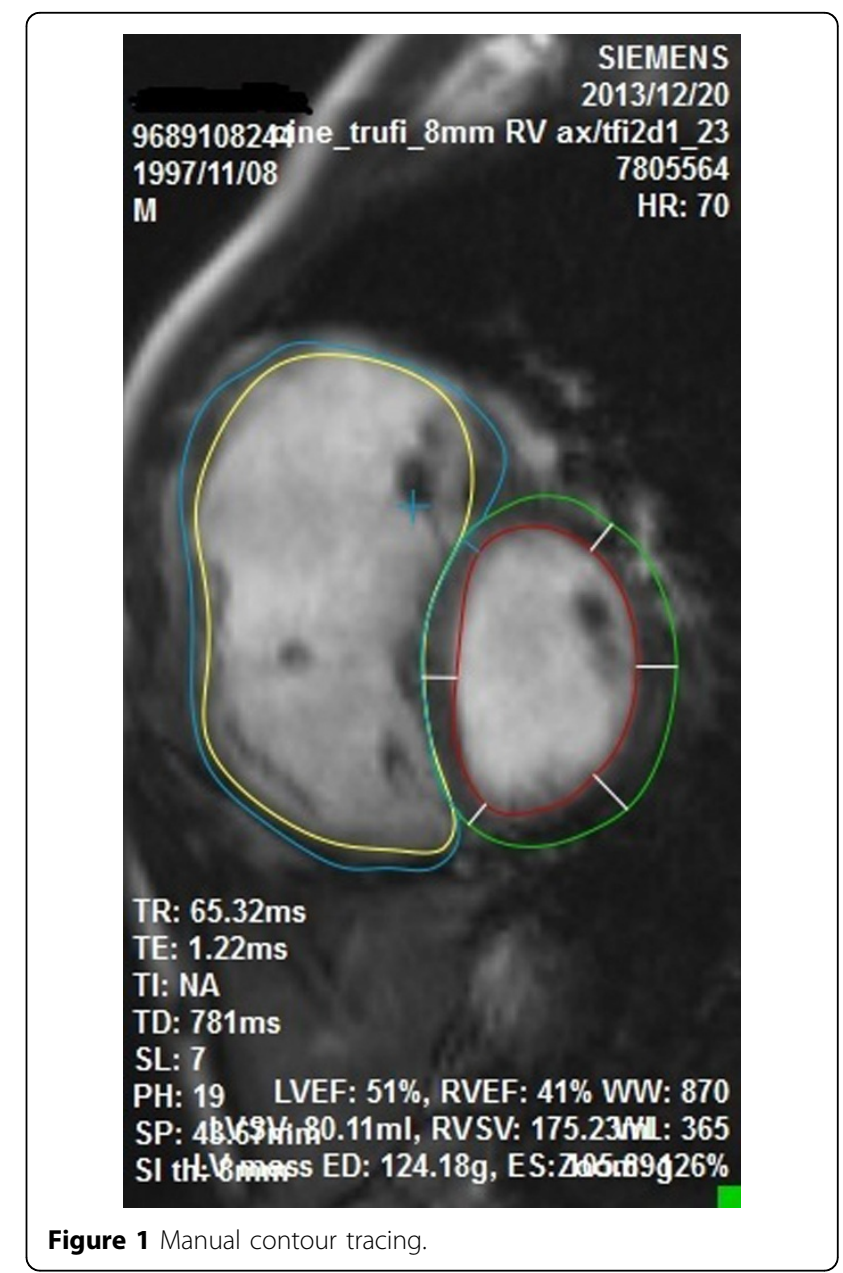




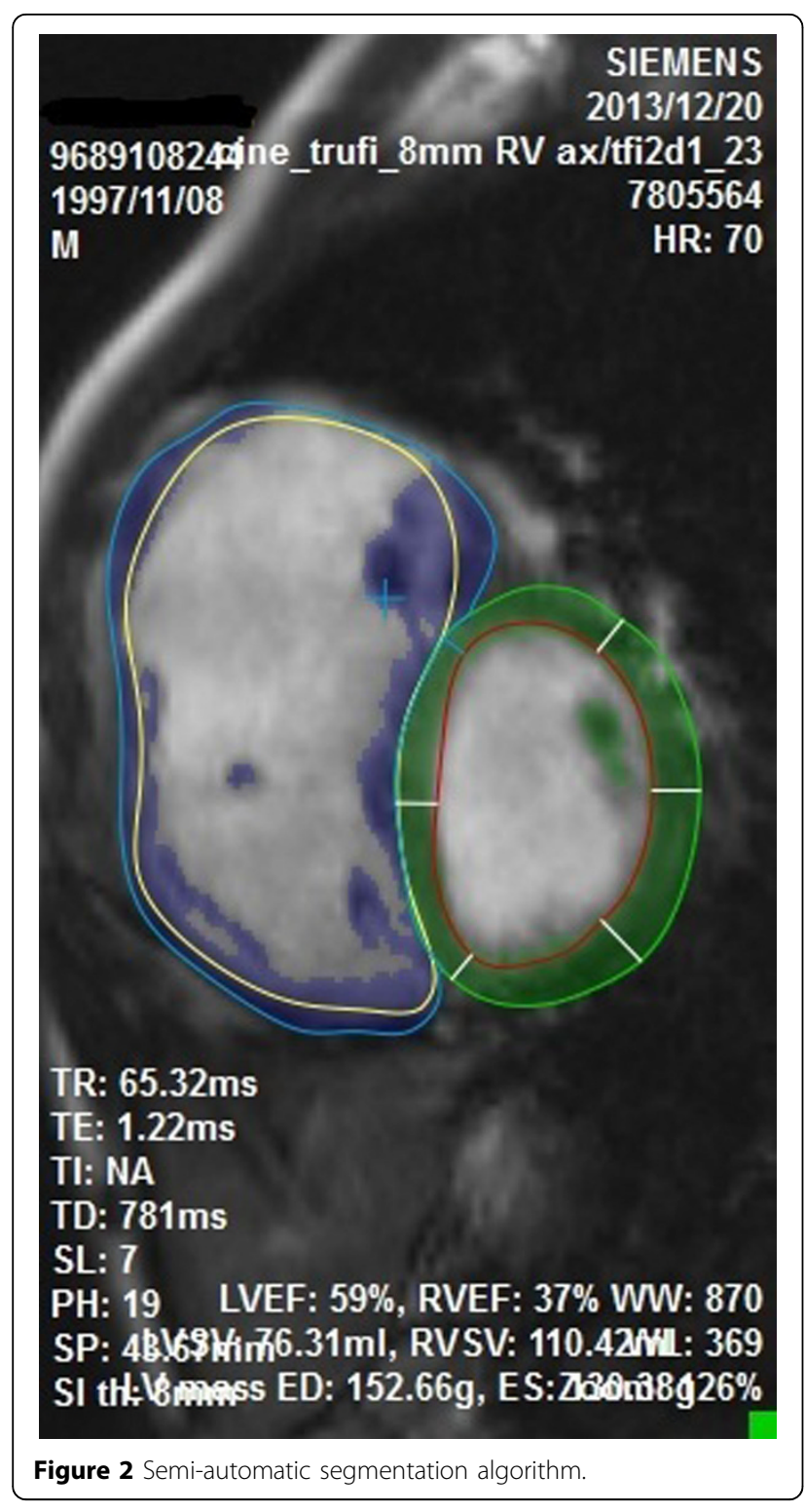

RVESV by $33 \%$ (from $108+/-67$ to $72+/-47 \mathrm{ml} / \mathrm{m}^{2}$, p < 0.005 ), RVSV by $25 \%$ (from $60+/-28$ to $45+/-29 \mathrm{ml} / \mathrm{m}^{2}$, $\mathrm{p}<0.005$ ) and the RVEF slightly increased by $7 \%$ (from $40+/-15$ to $43+/-19 \%, \mathrm{p}=0.01)$. RVSV measured by PAFV using PC $\left(42+/-24 \mathrm{ml} / \mathrm{m}^{2}\right)$ was more related with value measured by semi-automatic methods (mean difference $\left.=3.8 \mathrm{ml} / \mathrm{m}^{2}, \mathrm{p}=0.37\right)$ rather than the standard methods (mean difference $=18.3 \mathrm{ml} / \mathrm{m}^{2}, \mathrm{p}<0.005$ ) on MRI. In 32 cases, RVSV measured by ventriculographies $\left(53+/-18 \mathrm{ml} / \mathrm{m}^{2}\right)$ was more related with value measured by standard methods (mean difference $=2.1 \mathrm{ml} / \mathrm{m}^{2}, \mathrm{p}=$ $0.4)$ rather than the semi-automatic methods (mean difference $\left.=13.8 \mathrm{ml} / \mathrm{m}^{2}, \mathrm{p}<0.005\right)$ on MRI.

\section{Conclusions}

The measured RV volumes and function significantly changed by excluding trabeculae and papillary muscle. The new semi-automatic threshold-based segmentation software can reliably exclude trabeculae and papillary muscles from the RV blood volume.

\section{Funding}

None.

Published: 3 February 2015

doi:10.1186/1532-429X-17-S1-P73

Cite this article as: Inage and Mizuno: Impacts of right ventricular trabeculae and papillary muscles on volumes and function assessed by cardiovascular magnetic resonance using a novel software: semiautomatic threshold-based segmentation algorithm. Journal of Cardiovascular Magnetic Resonance 2015 17(Suppl 1):P73.

\section{Submit your next manuscript to BioMed Central and take full advantage of:}

- Convenient online submission

- Thorough peer review

- No space constraints or color figure charges

- Immediate publication on acceptance

- Inclusion in PubMed, CAS, Scopus and Google Scholar

- Research which is freely available for redistribution 